\title{
Smallpox stocks: new focus for research?
}

The US Institute of Medicine (IOM) has released a report asserting that stocks of live variola virus, the causative agent of smallpox, could be used to develop improved smallpox vaccines and antiviral agents. The report dovetails with a new initiative by the Department of Health and Human Services (HHS) to beef up the nation's defenses against bioterrorism, but stands at odds with the current World Health Organization (WHO) plan to destroy existing stocks of variola. By focusing on research applications for the stocks, the report also raises the question of whether research funding agencies other than the HHS will begin encouraging studies on live variola, work that has not been pursued in the US for at least two decades.

"Given that [smallpox] has no mammalian host other than man [thus making animal experi-

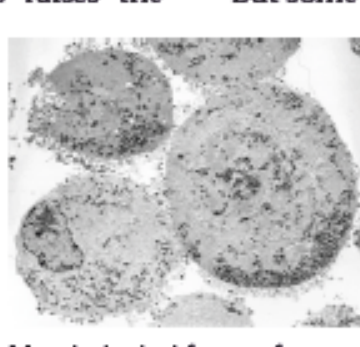

Morphological forms of vaccinia virus in infected BS-C-1 cells.
So it seems that the only potential source of funds is the new $\$ 1.4$ billion antibioterrorism effort, through which the HHS will receive $\$ 158$ million to establish and maintain vaccine and antibiotic stockpiles, train medical personnel, and fund research on agents likely to be used for bioterrorism, including smallpox, plague, anthrax and botulism.

But some experts suggest that the government's interest in biodefense might be a passing fad. Richard Condit, a poxvirus reii searcher and professor of Microbiology at the University of Florida as serts that "the anti-bioterrorism stuff is political

hype and journalistic hot air." Taking a slightly milder stance, Thomas Monath, vice president the work has to be done in the uncomfortable and cumbersome surroundings of a [biosafety level 4] facility, I doubt that any active research programs will be pursued," says Donald Henderson, who directed the WHO's smallpox eradication campaign and is now at the Johns Hopkins University Center for Civilian Biodefense Studies. Indeed, even Charles Carpenter, chairman of the IOM committee and director of the International Health Institute at Brown University, Rhode Island, admits that "it is unlikely that a great deal of work would be done on variola in the near future."

Despite the claims in the IOM report, many experts assert that vaccines and antiviral agents can be developed using other poxviruses. The current vaccine (Dryvax), manufactured by WyethLederle, consists of live vaccinia virus, a relative of variola; researchers at the US Army Medical Research Institute for Infectious Diseases have already completed Phase II clinical trials of a new vaccine developed using monkeypox virus as a test system. "The only reference I have ever seen to suggest that the [live variola] virus might be needed for a vaccine is in the recent IOM report," explains Henderson, who favors destroying existing smallpox stocks. for research at OraVax, Massachusetts, says "I give the present concern about [biological weapons] a five year period of
A visiting Japanese research fellow at the Mayo Clinic in Minneapolis, Yoichi Ito, has been charged with stealing research data and material from his host laboratory. Ito, who worked in the cartilage and connective tissue laboratory, had completed a two-year research fellowship and was due to return to Japan days before his arrest.

Ito's defense seems to be one of ignorance about the US regulations regarding intellectual property on scientific data (Nature 398, 448; 1999). However, an FBI search warrant affidavit states that Ito was informed of the rules on several occasions during his fellowship and was shown a video explaining the proprietary nature of research data two months before his anticipated departure.

In addition to copying his own research-which is permitted under laboratory policy-Ito also copied a large amount of data relating to projects he had never worked on, dating back to 1990. Ito's own gene-sequencing data
I grace. After that interest and funding will wane."

Though it is unclear how much funding will be earmarked for research into each biological agent, smallpox raises the most immediate policy concern if the live virus is to be studied because the last known stocks of variola are slated to be destroyed on June 30th, a decision which rests with the WHO. The WHO's World Health Assembly, consisting of representatives from 191 member states, is scheduled to meet on May 15th for a final vote on destroying variola stocks.

But according to David Heymann, Executive Director of Communicable Diseases at the WHO, a preliminary poll of Assembly members resulted in 79 responses, 71 favoring destruction of the stocks. Although the IOM committee was not asked to make a recommendation as to whether the virus should be destroyed, only to come up with possible uses for it if it were kept, it remains to be seen if its report-which could be said to represent the US government's position-will sway the Assembly.

ALAN Dove, NEW YoRK

\section{Researcher charged with data theft}

could not be located on the central computer and his laboratory notebooks and key tissue slides are also missing. The evening before Ito was to fly to Hawail to get married on March 18th, a security officer found him taking photographs of laboratory equipment.

Moreover, according to the affidavit, Ito's Lab Supervisor, James Fitzsimmons, claimed that when research fellows join the Clinic, they are presented with written and verbal instructions that all work products, including original notes, are laboratory property. Another Japanese researcher, Takumi Fukumoto, at the laboratory, confirmed this and noted that in January all scientists, including Ito, were shown a "Mayo Integrity Video," which repeated the message that their work was the property of the clinic.

Pending his preliminary hearing, Ito has been released on bail of $\$ 25,000$, and was ordered to surrender his passport, remain within Minnesota and report regularly to the court.

STEPHEN CASS, NEW YoRK 